\title{
MÁRIO DE ANDRADE: TURISTA APRENDIZ EM TERRA ARRASADA, DA AMAZÔNIA A SÃO PAULO, ATÉ DIZER CHEGA
}

\author{
MÁRIO DE ANDRADE: NA APPRENTICE TOURIST IN A WASTELAND, FROM AMAZONIA TO \\ SÃO PAULO, UNTIL IT'S ENOUGH
}

https://orcid.org/0000-0001-9850-0190 Marcia Aparecida Gobbi ${ }^{\mathrm{A}}$

(1D) https://orcid.org/0000-0001-7547-0881 Joseane Búfalo ${ }^{\text {B }}$

\author{
${ }^{\text {A }}$ Universidade de São Paulo (USP), São Paulo, SP, Brasil \\ ${ }^{\text {B }}$ Prefeitura Municipal de Campinas (PMC), Campinas, SP, Brasil \\ Recebido em: 13 dez. 2021 | Aceito em: 30 jan. 2022 \\ Correspondência: Marcia (mgobbi@usp.br); Joseane (jmbufalo@gmail.com)
}

\section{Resumo}

O objetivo deste ensaio é apresentar algumas reflexões sobre os tempos atuais em determinadas regiões brasileiras articuladas a algumas impressões presentes em textos de Mário de Andrade, sendo eles: seu diário de viagens denominado O Turista Aprendiz, o conto "Primeiro de Maio" e excertos de cartas conjugadas com fotografias feitas por Mário de Andrade e outras, recentes, de textos jornalísticos e sites livres. Sem a pretensão de apresentar discussões teóricas sobre uso de imagens, elas nos servem como inspirações para pensar sobre e a partir de diferentes temporalidades. Ao comemorarmos 100 anos da Semana de Arte Moderna, reunimos brevemente aspectos da obra de Mário além da Semana, que se oferece como fundamental para os desdobramentos posteriores em sua obra literária e política. O que é possível pensar neste quase um século de viagens e 100 anos de Semana de Arte Moderna? Trata-se de "uma" semana de arte entre tantas outras possibilidades em curso para abordar arte moderna no país. São registros em formas de cenas sem a pretensão de cobrir todo o pensamento andradino e nem mesmo os acontecimentos mais recentes. Por ora, provocar pensamentos a partir das transformações históricas em médio e curto períodos é nosso objetivo.

Palavras-chave: Mário de Andrade; Cidade; Semana de Arte Moderna; Desigualdades sociais; Turista Aprendiz.

\begin{abstract}
The purpose of this essay is to present some reflections on the current times in certain Brazilian regions articulated to some impressions present in texts by Mário de Andrade, being them: his travel journal called O Turista Aprendiz, the short story "Primeiro de Maio" and excerpts from letters combined with photographs made by Mário de Andrade and others, recent ones, from journalistic texts and free websites. Without intending to present theoretical discussions on the use of images, they serve as inspiration to think about and from different temporalities. As we commemorate the 100th anniversary of the Week of Modern Art, we briefly bring together aspects of Mário's work beyond the Week, which offers itself as fundamental to later developments in his literary and political work. What is it possible to think about in this almost a century of travel and 100 years of the Week of Modern Art? It is about "one" art week among so many other possibilities in course to approach modern art in the country. These are records in the form of scenes without the pretension of covering the whole of Andradino's thought and not even the most recent events. For now, our objective is to provoke thoughts based on historical transformations in the short and medium term.
\end{abstract}


Keywords:Mário de Andrade; City; Week Modern Art; Social inequalities; Apprentice Tourist.

\section{Primeiras palavras para compreender a terra em vias de arraso}

O dossiê "Por uma pedagogia macunaímica: infâncias, estudos decoloniais $e$ resistências plurais na contemporaneidade”, dedica-se a dois temas: 100 anos da Semana de Arte Moderna em São Paulo e os 25 anos do Grupo de Estudos e Pesquisas em Diferenciação Socioculturais, Culturas Infantis (GEPEDISC). Trata-se de uma junção ousada e bastante oportuna, pois dos 100 anos de Semana, passamos 25 fazendo pesquisas com e sobre infâncias dentro do referido grupo. Isto se fez especialmente porque grande parte das propostas e investigações deste grupo inspiram-se e estão fundamentadas nos campos das artes, numa pedagogia macunaímica (a ser mais bem definida por Ana Lúcia Goulart de Faria, neste dossiê) e em Mário de Andrade, literato, e sua prática estético-política quando diretor do Departamento de Cultura da cidade de São Paulo. Ele era colecionador de desenhos feitos por crianças, o que confere à parte de sua obra a possibilidade de o chamarmos de criancista, entre outras tantas produções e contribuições, que alicerçam interpretações sobre o Brasil, esta terra que estamos chamando aqui, dado o contexto econômico, social e político em que escrevemos o ensaio, de "terra arrasada".

Inquietas, resolvemos enfrentar este enorme desafio e a oportunidade para pensar a partir destas influências que constituem parte da formação acadêmica das autoras deste ensaio - membras do GEPEDISC desde sua fundação. Não pretendemos, nem de longe, que o ensaio tenha um caráter conclusivo, muito menos esgotar temáticas tão amplas e complexas, mas propor algumas reflexões enganchadas no pensamento de Mário de Andrade, registradas em alguns de seus textos em diário, cartas e contos que seguirão uma brevíssima e inicial reflexão sobre a Semana de Arte Moderna em São Paulo, da qual o autor foi protagonista.

Algo nos conduz à escrita deste ensaio: reconhecer que escrever é registrar politicamente o que se pensa e parte do posicionamento tomado; e reconhecer que a escrita pode enlaçar pensamentos nesta travessia para um suposto fim desse período e produzir outros tempos melhores ao forjar saídas coletivamente. Nesse ensaio, escrever é tratar desse tempo que é passado e presente conjuntamente - nele mesmo. Nosso objetivo é um tanto desafiador, a saber, pretendemos articular a alguns dos acontecimentos atuais reflexões e impressões de Mário de Andrade em O Turista Aprendiz e no conto "Primeiro de Maio", buscando estabelecer 
um diálogo em confidência com Mário ${ }^{i}$. Em algumas passagens, apresenta-se um gênero epistolar escrito em primeira pessoa do plural e destinado ao Mário de Andrade, como a estabelecer certo diálogo. Neste ano, tantas comemorações e reflexões serão feitas a propósito dos 100 anos da Semana de Arte Moderna de 1922. Semana criada no ano de comemorações do Centenário da Independência do Brasil. Duzentos anos depois, parece que, apesar de tantas publicações, ainda há muito a refletir sobre o que significou este processo de se independer dependendo. Destaca-se aqui que se trata de "uma" semana de arte moderna num país em que se fazia arte moderna em diferentes estados, não sendo São Paulo, "comoção de minha vida" (ANDRADE, 1976, p. 39), o trem a puxar todo o restante do país no que se refere à produção artística e cultural. Ao questionarmos o passado que não passa, questionamo-nos também sobre o que foi e é alijado dos povos brasileiros e suas produções culturais e artísticas, preocupandonos com públicos amplos que incluam a todos.

Joseane, Marcia e Mário, em tempos históricos distintos, propõem-se a um encontro possibilitado por imagens, textos escritos a partir de uma viagem e um conto. Apoiamo-nos num outro tempo, tão próximo historicamente, mas que se distancia - e se oferece como recurso para entendimento do presente - ao aprofundar constantemente as desigualdades, as crises que se agravaram nos últimos anos, mas que denotam a terra arrasada, como denominamos aqui. Arrasada pelo fogo que ao queimar nos faz arder sabendo dos rumos aparentemente incertos e que nos coloca diante de uma tragédia que precisa ser encarada de frente com a certeza de que não se quer voltar a ser o que era, ao lugar onde estávamos, que para isso faz-se necessário abrir mão de relações cujo formato cristalizado insiste em permanecer, mesmo quando afirmamos que não, em um uso exacerbado de jargões que nada mais faz do que apaziguar algumas sensações de que não nos colocamos criticamente no mundo. Relatos de viagens são frutíferas formas de levar leitores e leitoras a outras paragens, por vezes, nunca pisadas, mas que se materializam em imagens recriadas a partir do escrito e se tornam lugares envolvidos às nossas memórias e projeções de outros tempos. Diferentes temporalidades estão aqui mescladas. Esses tempos estão em nós e fazem-se presentes também nessa escrita, diríamos que a conduz.

Há um século, poucos anos mais, Mário de Andrade, durante o período da Semana de Arte de 22, depois, anteviu e investigou o Brasil entrando no mundo urbano industrial, tendo em São Paulo uma das maiores expressões deste processo. Multidões, automóveis, aeroplanos não alteravam paisagens citadinas apenas, mas mentalidades de quem vivia na cidade. Tamanho dinamismo chegou a compor desenhos das crianças frequentadoras dos Parques Infantis, por ele idealizados, em que aeroplanos e dirigíveis ganhavam a centralidade das folhas A4, 
expressando o que se passava, não apenas nos céus da grande e futura cosmopolita cidade, mas nas mentalidades que iam se modificando ao vê-las e pensavam num presente em franca projeção de tempos vindouros.

Figura 1 - Desenho elaborado por José Jardim Santos, Parque Infantil da Lapa, 1935/1938 Concurso de desenhos infantis

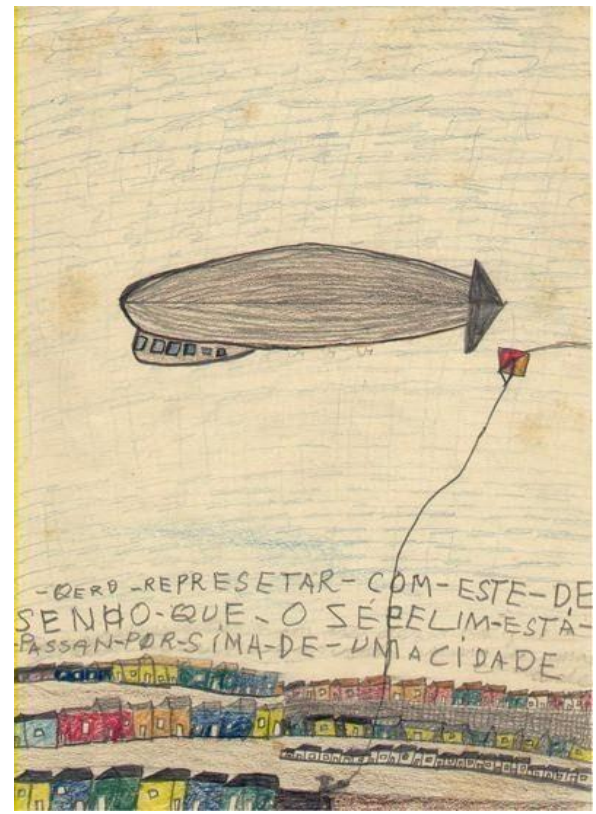

Fonte: Coleção de Desenhos Infantis. Acervo Mário de Andrade IEB-USP

É a cidade "comoção de muitas vidas" que se apresenta arlequinal em multiplicidade e diferenças. Testemunha de mudanças, Mário de Andrade é intérprete de um país que se transforma e se moderniza, traduzindo a ideia de Brasil moderno (IANNI, 2004) em que se via uma economia adiantada ao mesmo tempo em que a realidade social, política e cultural caminhava e ainda caminha com lacunas profundas. Em suas viagens, ao buscar o chamado Brasil profundo, depara-se com a extrema desigualdade já existente há muitas décadas. A sociedade dividida em classes faz surgir com mais intensidade o poeta e homem político engajado. Estava nos anos 1930/40 e se avistava a presença que reunia arte e política em sua pessoa e projetos culturais e sociais, em destaque no Departamento de Cultura, primeiro órgão criado para se pensar sobre cultura no país e por ele chefiado entre os anos 1935-1938, na gestão do prefeito Fábio Prado, também modernista.

Deixou em suas cartas e seus diários importantes reflexões sobre o visto, o vivido em diferentes regiões brasileiras e o proposto para tantas delas. Para a elaboração deste ensaio, além dos textos já mencionados, consideramos imagens. Fotografias feitas por Mário de Andrade em suas viagens que nos inspiram a pensar o agora a partir das regiões visitadas 
outrora. As fotografias estão contidas em O Turista Aprendiz que nos tocaram. Mário reúne aos elementos plásticos as informações sobre recursos usados para fazer fotar, neologismo criado por ele, referindo-se ao fazer a fotografia, a isso juntavam-se as denominações cunhadas por Mário e escritas atrás das imagens, estas informações favorecerão bastante a quem fará uso destas fotos como objeto de pesquisa. Ao incluirmos fotos publicadas recentemente sobre o desmatamento e o garimpo na Amazonia ${ }^{\mathrm{ii}}$, não se pretende comparar ontem e hoje, ou o que fora descoberto em suas transformações e permanências. O objetivo é menos pretensioso. Tratase apenas de inquietações oriundas das conhecidas preocupações de Mário de Andrade com o Brasil. Uma possível pergunta: qual a relação disto com a Semana de Arte Moderna de 1922, também protagonizada por Mário de Andrade? Ao focarmos em Mário de Andrade, encontramos nele a presença da busca constante por descobrir o Brasil e brasis, busca essa que está, a seu modo, contida na Semana pelo desejo que a organiza e a propõe como ruptura em diferentes campos das artes. Não pela reverência que poderia mover esse ensaio, mas pela referência que nos instiga a ir além.

Este ensaio será apresentado em três cenas isoladas. São elas: Semana, semanas: força fatal que inspira e coloniza; Terra arrasada 1: fotando, tudo é árvore, mas arde como brasa; e Terra arrasada 2: chegando nas cidades de Campinas e São Paulo e a educação que lacrimeja sob o gás.

Nesta proposta bricolada de escrita a quatro mãos, temos algumas inspirações, como já afirmado. Não podemos nos esquivar de afirmar que a Semana de Arte Moderna se comporta como mais que uma efeméride apenas, ou uma narrativa épica sobre a história do modernismo brasileiro que pode deixar - se não deixou - certa marca universal, alicerçada na elite cafeeira paulistana e seus mecenas e produzida como força fatal, como escreveria Mário de Andrade no balanço do modernismo vinte anos após a Semana ter acontecido. Não somos favoráveis aos cancelamentos que poderiam silenciar este momento tão importante e o modernismo paulista, pensamos criticamente que ao rever o período revisamos certo triunfo inventado de uma certa locomotiva cultural do país. Há que colocar a Semana em perspectiva temporal e geográfica em que os entrecruzamentos de interesses e condições devem ser considerados. São Paulo, porém, nas palavras de Mário, era mais moderna, sendo urbanizada, estava mais em contato com a atualidade do mundo, isso explicado por sua industrialização, ainda que no provincianismo que a caracterizara (ANDRADE, 1974, p. 238).

Interessa-nos, contudo, pensar sobre os arredores do local onde a Semana acontece. O Teatro Municipal de São Paulo apresenta-se como muito emblemático, nos toma de dentro para 
fora para nos situarmos no ontem com a Semana, e, no hoje com suas ruas, que, outrora europeizadas, agora se mostram como suportes e pano de fundo da miserabilidade que nos acomete de corpo e alma, estampada pelas ruas, praças e avenidas. A narrativa se fragiliza quando olhamos ao redor. A Semana e a tessitura que a formou nos remetem a muitas questões, algumas das quais estão neste primeiro momento do ensaio.

Na segunda parte desta colagem de pensamentos em conexão, apresentamos o Terra arrasada 1: fotando, tudo é árvore, mas arde como brasa. A partir da leitura do livro-diário O Turista Aprendiz e dos relatos de viagem de Mário de Andrade nos inquietamos ainda mais. Fomos tomadas pelas emoções deixadas por sobre as ruínas em brasa em que tem sido transformada grande parte dos locais visitados e apreendidos pelo poeta em expedições realizadas para o Norte e Nordeste do Brasil nos anos de 1927 e 1928/29. O modernista da Semana, que em 1942 afirmou que "somente uma figura como Paulo Prado e uma cidade grande, mas provinciana como São Paulo, poderiam fazer o movimento modernista e objetiválo" (ANDRADE, 1974, p. 235), passaria por transformações enlevadas por críticas e sensibilidade exacerbada frente as produções culturais de povos indígenas, ribeirinhos e dos interiores do país em regiões pouco conhecidas. Ele, modernista em seu cotidiano, ligava-se à Semana, desdobrando-a em formas de ver, contatar e se transformar em viagens, ou, a partir delas.

Contudo, ao lermos seu diário, que entendemos inflamado de uma vivacidade própria das boas e inusitadas descobertas, fomos impulsionadas pelo contexto e condições em que vivemos a pensar sobre o que foi visto e o que temos estampado fazendo arder os olhos pelas brasas que carcomem o Brasil.

Finalmente, em Terra arrasada 2: chegando nas cidades de Campinas e São Paulo e a educação que lacrimeja sob o gás, temos uma aproximação com questões cotidianas. Não pensamos que há um afastamento em relação à Semana, mas, sim, que ficamos mais perto de temas tratados pelo GEPEDISC, em especial, por aquelas que fazem a educação pública de crianças brasileiras. Trata-se de mais uma colagem possível inspiradas, sem comparar, nos usos dos espaços urbanos como pensados por Mário, mais recentemente por bombas de gás que intimidam manifestações de funcionárias e funcionários públicos, professoras majoritariamente em busca da manutenção de seus direitos. Mário, também funcionário público do município de São Paulo, ficaria estupefato certamente. $\mathrm{O}$ arraso da terra se desdobra em mil faces.

Ressaltamos que, embora apresentemos fotografias e um desenho infantil ao longo deste ensaio, ele não tem como foco qualquer estudo de imagens. Elas não estão como ilustrações, 
seguramente, mas em diálogos com o texto escrito. Dentro dos limites e objetivos desse ensaio, não nos comprometemos a fazer discussões teóricas sobre uso da imagem, embora saibamos tratar-se de algo importante. Encontram-se aqui no que acreditamos compor as reflexões, não sobre elas, mas que nos instigam a partir delas.

\section{Semana, semanas: força fatal que inspira e coloniza}

Parece-nos inegável a importância da Semana de Arte Moderna de 1922, os questionamentos apresentados à arte praticada até então e seus desdobramentos. Ela é muito mais que uma efeméride à toa, comemorada por força da tradição comemorativa. A Semana cultivou forma e conteúdo transformando práticas culturais e posturas daqueles que passaram a participar de encontros em torno das artes. Porém, entendemos que apesar dessa inquestionável importância, trata-se de uma Semana entre tantas outras acontecidas em regiões diferentes, com grupos diversos e, talvez, mais includentes e voltadas ao público mais amplo, composto por pessoas pobres e detentores de outra cultura que não a avaliada como alta cultura, ou não apoiada pela aristocracia e produtores de café.

Acreditamos que é fundamental refletir sobre ela para que cheguemos a outras conclusões que remetem a questionar o caráter universal do modernismo, como se o que ocorreu em São Paulo se comportasse como a locomotiva a puxar todo o restante do país. De modo paradoxal, Sérgio Vaz, conhecido poeta e articulador do Sarau da Cooperifa, afirmou a propósito dos 85 anos da Semana de Arte Moderna:

Inspirada na Semana de Arte Moderna de 22, a Cooperifa propõe sacudir o marasmo cultural que se instalou no país. Uma Semana inteira de artes para que a bússola do país, que aponta para o centro, também aponte para a periferia (VAZ, 2007, p. 2).

Interessante modo de abordar, talvez antropofágico, em que se alimenta da forma da Semana, de caráter elitista, para compor o Sarau e seus conteúdos, cuja característica predominante é a presença da arte periférica e na periferia, voltada, fundamentalmente, para moradores e moradoras de todas as idades. Importante recuperar esta prática quando discutiremos sobre a Semana num ano tenso e preocupante, num país cuja frágil democracia, exige formas e conteúdos combativos com todas/es/os considerando classe social, gênero e raça. Acreditamos que a fala de Sérgio Vaz permite questionar a contrapelo a própria Semana, seus propósitos e participantes, sem deixar de lado sua importância. Permite indagar sobre o que a Semana nos diz acerca do país à época e atualmente. O referido Sarau e tantos outros, que 
podem ser vistos como desdobramentos inspirados na Semana, seriam também uma reparação da exclusão existente há séculos? Em 2019, a presença do rapper paulistano Emicida no Teatro Municipal no show intitulado Amarelo, remete a uma resposta. Ele, jovem negro, e parte de seu público, historicamente alijados de muitas manifestações culturais, estariam presentes em 1922? Ao pensarmos sobre o que a Semana apresentava a respeito do país à época e hoje, a presença do rapper nos informa sobre mudanças, ainda que incipientes na produção e recepção das artes.

Esse ensaio não pretende se debruçar em estudos sobre a Semana de Arte Moderna, deixamos apenas algumas questões para futuras investigações, que a nosso ver se enlaçam ao que virá nas próximas partes, já que pensar sobre a Semana é pensar no que foi e ainda é arremessado para fora dela.

Ao colocarmos a lume Mário de Andrade nos aproximamos de suas viagens, a busca incessante pelos povos do Brasil, pelo que havia de união, e o que depois foi percebido como desigualdades e diferenças, com o que ele vai se deparar em suas andanças, desdobrando-se em reflexões, participação e propostas políticas demonstrando suas interpretações do Brasil. O escritor modernista da Semana de 22, lucidez em ação, intérprete do Brasil, tem sua presença reclamada por nós, não em caráter conclusivo, o que seria anacronismo, mas apenas em alusão ao tempo que se transforma e arde diferentemente em nós.

\section{Terra arrasada 1: fotando, tudo é árvore, mas arde como brasa}

Tempos sombrios. Tempos de tragédia. Tempos difíceis. Frases proferidas com frequência nos últimos anos. Inferimos que esta repetição tem levado a certa naturalização de seus sentidos mais profundos. Com diferentes nuances, todas se referem ao período em que estamos vivendo nos últimos anos no Brasil e no mundo. Refletem o que é visto e percebido com maior ou menor tragicidade a depender de onde nos encontramos nesta história. Não há como discordar ou até mesmo deixar de acrescentar outros tantos comentários não menos verdadeiros: entramos numa recessão econômica; aprofundamento da histórica miséria no Brasil; agudização da violência, especialmente contra o povo negro, pobres, jovens, mulheres e crianças; retirada de direitos e ausência de investimentos em projetos culturais, educação, saúde, moradia; terraplanismo; ciência posta em descrédito. São muitas as misérias multiplicadas num país que não é para principiantes, como já disse Tom Jobim, referindo-se ao Brasil décadas atrás. Essa destruição sistemática de vidas, tornando-as cada vez mais precarizadas, encontra-se como parte de um constructo que não teve início nos últimos dois 
anos devido à pandemia ocasionada pelo vírus Sars-Cov-2, mas neles se recrudesceu, exige tomadas de posicionamento político e a produção de muitas reflexões feitas durante uma grande tempestade, uma catástrofe, cujo fim parece estar distante, sobretudo quando nos deparamos com índices de pobreza e desemprego. "O passado é lição para se meditar” (ANDRADE, 1987, p. 75), é neste passado que não passa, que está em nós inscrito pelas mãos coloniais implicadas em relações violentas acometidas cotidianamente que nos fiamos para pensar e escrever.

Nossa busca é tão somente apresentar elementos para a continuidade de reflexões sobre um tempo triste e exigente. Trata-se da aproximação com uma bricolagem de tempos ligados a assuntos similares num país cuja população, que afirma "sou brasileiro e não desisto nunca" iii, parece dar sinais de sofrimentos e cansaços intensos apontando para a urgência de mudanças estruturais, num momento em que urge tomar posição. De que lado estamos é uma pergunta que ressoa constantemente.

Encontramos muito de tudo nos registros escritos, desenhos e fotografias de viagens de Mário. O todo está contido nelas e podemos olhá-las e lê-las, obtendo indagações e respostas à moda de cada um que olha. Eles nos convidam a pensar sobre as fronteiras ou, quem sabe, a elaborar outras. Há algo que nos toca de modo profundo, por que não, doído: trata-se do registro de lugares e tempos que, afirmamos novamente, literalmente ardem em fogo, seja nas florestas visitadas em que Mário de Andrade percorria descobrindo brasis e suas gentes, seja nas ruas da cidade, tão amada e descrita por Mário. A pauliceia, cujo desvario fez-se em disputas, ainda mais intensas, em que pessoas vivem a perda de direitos diariamente, a saber, professoras de instituições públicas, similares às que Mário atuou também como funcionário público e político implicado em ações culturais da cidade. Nelas encontram-se milhares de pessoas cujos tetos se dissolvem sobre as cabeças tornando-se o céu de quem não tem onde morar e ocupa ruas e mais ruas, edifícios, terrenos cujos proprietários avidamente aguardam a valorização da terra. Tratase da "força da grana que ergue e destrói coisas belas", como diria canção de Caetano Veloso, e impede a existência do outrora suave aroma das flores paulistanas, como descreveu Mário décadas atrás.

Nos relatos de $O$ Turista Aprendiz, Mário mescla o estilo e invenções literárias a análises de fundo sociológico e político. Não podemos nos furtar a afirmar que isso em muito nos instiga a conhecer as cenas narradas em suas complexidades página a página e que nos convida a revisitar, com poucos recursos, as ideias e os locais vistos pelos olhos do modernista.

Turistando com a leitura d'O Turista Aprendiz nos sentimos provocadas a pensar sobre alguns dos locais percorridos nas chamadas viagens etnográficas de Mário de Andrade e suas 
amigas e seus amigos modernistas e registrados em seus diários. Inspiramo-nos no encantamento produtor do poeta engajado confrontando-o com os tempos em que nos encontramos atualmente. Como num brevíssimo sobrevoo, escrevemos esse ensaio no fechar de portas do ano de 2021. Completamos quase dois anos de uma pandemia que levou, até o momento em que escrevemos esse ensaio, quase 700 mil pessoas no Brasil, mortes que poderiam ter sido evitadas e outras tantas mortes, tantas que nos extirpam os desejos de prosseguir, somos vítimas e coniventes com muitas mortes, sabendo que há muitos jeitos de matar e morrer, inclusive sob tortura em praias famosas ${ }^{\text {iv }}$. Faltam poucos dias para o Peru de Natal - remetendo-nos ao conto de Mário de Andrade, publicado em 1947, e o que ele nos apresenta sobre reuniões em família. Momento em que um pequeno grupo social poderá esbanjar o peru, empadinhas e doces, e grande parte das gentes apenas observará os ossos que dele sobraram em que se refestelaram e, talvez, até brigarão por eles, ou os esperarão ávidos quando jogados na manhã do dia seguinte em locais de descarte de alimentos em grandes centros urbanos do país.

Em excertos da obra $O$ Turista Aprendiz, Mário de Andrade nos apresenta bons elementos para pensar sobre outros povos e lugares.

07 de maio de 1927: Partida de São Paulo. [...].

Não fui feito pra viajar, bolas! Entro na cabina, agora é tarde, já parti, nem posso me arrepender. Um vazio compacto dentro de mim. Sento em mim.

18 de julho: Os índios Do-Mi-Sol: Lenda do aparecimento do homem. Então os índios me levaram ver a tal de embaúva colosso. Era realmente um prodígio. No meio da serrapilheira densa bem mais alta que a altura de um homem, os troncos colossais daquela floresta verdadeiramente virgem se lançavam pro alto com fúria, troncos que sete pessoas de mãos dadas mal conseguiam cercar pela metade (ANDRADE, 2015, p. 50).

Telê Ancona Lopez (2005) afirmou que Mário de Andrade foi um fotógrafo moderno, mas de reconhecimento tardio. A pesquisadora, em seus estudos, compreende o interesse tecido ao longo de muitos anos pelo poeta em conhecer o Brasil, encontrando-se em maior profundidade em suas viagens a Minas Gerais e, ainda mais, aquelas realizadas para o Norte e Nordeste do país, respectivamente nos anos 1927 e 1928/9. É nos estados da região norte que o fotógrafo moderno surge em sua forma mais intensa. Isso resulta de vagaroso aprendizado autodidata a partir de revistas alemãs que lhe chegavam e o conduziam a um mundo de poses, luzes, cores, assuntos, cenas. A fotografia compõe a viagem e nos coloca dentro dela, ora de modo surreal, ora com as gentes captadas pela Codaque ${ }^{v}$, em suas ações, as mais cotidianas. São rastros de suas passagens pelo Brasil e seus vizinhos Peru e Bolívia marcados em imagens. 
Figura 2 - A Vitória do Madeira, 1927, Mário de Andrade (fotografia)

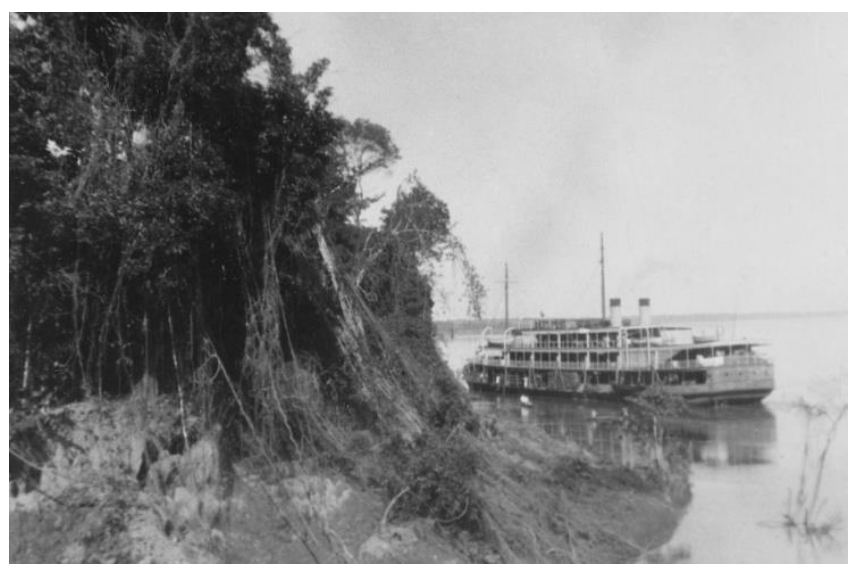

Fonte: acervo IEB-USP.

Figura 3 - Maquinário para mineração no Rio Madeira, Amazonas, 2021

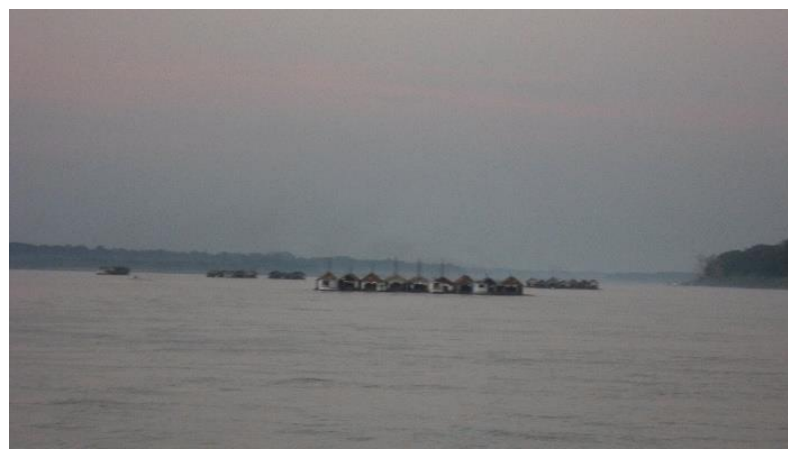

Fonte: File Garimpo sobre o rio Madeira. Wikimedia Commons

Mário de Andrade viajou pela Amazônia em 1927. Suas pesquisas etnográficas, registros de turista aprendiz e curioso, bem como as fotografias feitas por ele implicam quem as vê, as águas e moradores ribeirinhos e ribeirinhas, crianças ou não, indígenas, caboclos, tantas pessoas e suas artes de fazer a vida cotidianamente. Trata-se de expressões do interesse de Mário e demais modernistas por conhecer a chamada cultura nacional. As viagens eram recursos alimentados pela curiosidade e urgência impostas por eles mesmos para entenderem a cultura brasileira esparramada por todas as regiões. Danças, músicas, falas, gestos são objetos de investigações andradinas. Encarnam-se posteriormente em suas obras, Macunaíma é uma expressão bastante conhecida deste encantamento e descobertas. Ao ir para Amazônia, já estava muito ligado à cidade de São Paulo com suas multidões, o mundo que se transforma parecia encontrar-se em vibrações dentro do poeta. Era um testemunho de quem vivia nesse país e buscava compreendê-lo, interpretando-o ao mesmo tempo em que o sorvia com o corpo todo, fotando e escrevendo. 
Contudo, ao longo do processo de transformações geográficas, históricas e sociais, a Amazônia vem sofrendo profundas mudanças. Hoje grande parte da floresta arde em brasa. Explorações de minério, queimadas e desmatamentos de áreas que equivalem a um campo de futebol a cada 6 segundos.

Figura 4 - Devastações na Amazônia.

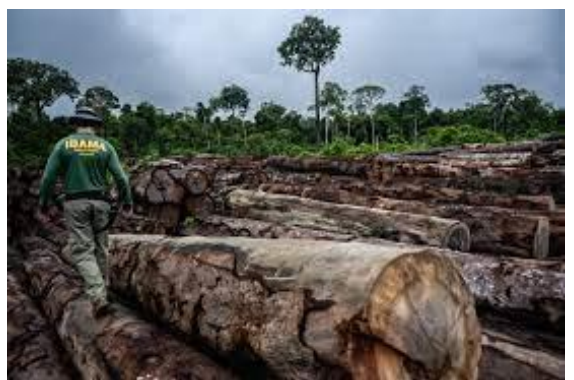

Fonte: File Garimpo sobre o rio Madeira. Wikimedia Commons

Figura 5 - Operação Verde Brasil-Amazônia 2021

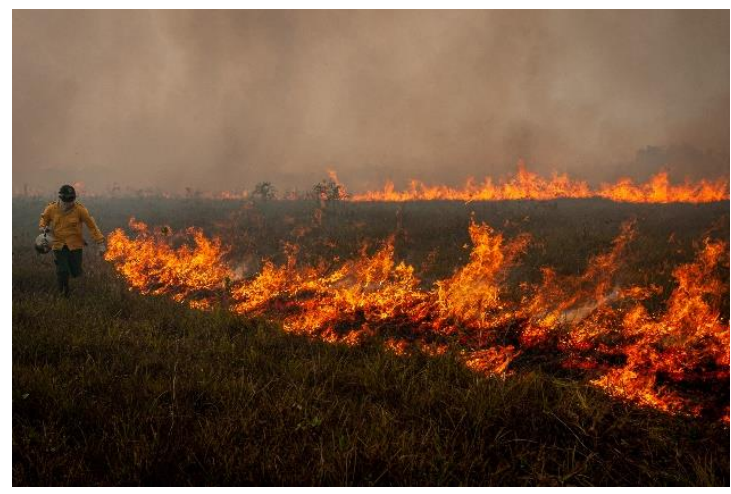

Fonte: Wikimedia Commons.

Desmatar. Este é o verbo mais conjugado nas últimas décadas, acirrando-se nos últimos anos em que um ministro, ocupante da pasta do Meio Ambiente, proferiu a seguinte frase em meio a uma reunião ministerial: "vamos deixar a boiada passar". Tratava-se de desconsiderar desmatamentos, explorações e extermínios, enquanto a mídia estava atenta à Covid-19 ${ }^{\mathrm{vi}}$, e explorar a Amazônia em seu ponto máximo possível extraindo dela tudo o que pudessem. E isso, mais do que como profecia, se fez verdade, e as porteiras, já abertas, ficaram escancaradas para que o pior pudesse passar diante de vistas grossas.

Duas crianças yanomami mortas, sugadas por uma draga da exploração ilegal de minério

Dois meninos, de 4 e de 7 anos, morreram afogados, ao que tudo indica, por ação do maquinário usado para garimpo enquanto brincavam às margens de um rio em Roraima, denunciam indígenas (JUCÁ, 2021, s/p). 
No dia 12 de outubro de 2021, quando se comemora o Dia das Crianças, mais uma tragédia acontece a este país. Dois meninos yanomami com idade de 4 e 7 anos foram dragados por máquinas mineradoras. A denúncia do Conselho de Saúde Indígena Yanomami e Ye’Kuana, embora tenha reverberado entre estudiosos das temáticas indígenas e ecológicas e parte de uma população já indignada e atenta ao que nos acomete, pouco conseguiu para alterar estruturalmente essa condição. Há uma exploração ilegal de minério, bastante conhecida e denunciada. O governo Bolsonaro faz vistas grossas e ouvidos moucos aos pedidos dos indígenas para que retirem 20 mil garimpeiros do local. A negligência com os povos indígenas é absoluta. Isso não basta, como afirmou Tasso Azevedo ${ }^{\text {vii }}$, coordenador do MapBiomas, o fogo que gera o desmatamento é criminoso, não é devido à floresta cuja umidade impediria o fogo. O presidente da República? Em diferentes palanques, ele responde dizendo que os ataques sofridos por ele são injustos e que faz o possível para conter esses problemas.

Este triste cenário é reflexo das injustiças cotidianas às quais temos notícias e de algum modo participamos como vítimas e corresponsáveis pelo silenciamento em que muitos nos mantemos numa suspensão-expectativa de um futuro ou como se uma crise maior fosse necessária para nos despertar, como questionou Slavoj Zizek (2021) que reclama do pouco comprometimento exposto em reuniões mundiais como as de Glasgow recentemente, cujo objetivo era discutir e encontrar saídas mundiais para o clima e os desdobramentos da permanência do crime ambiental em larga escala, o recém-denominado ecocídio em que estamos vivendo.

Terra arrasada 2: chegando nas cidades de Campinas e São Paulo e a educação que lacrimeja sob o gás

Figura 5 - Manifestação de professoras e professores do município de São Paulo, 2021

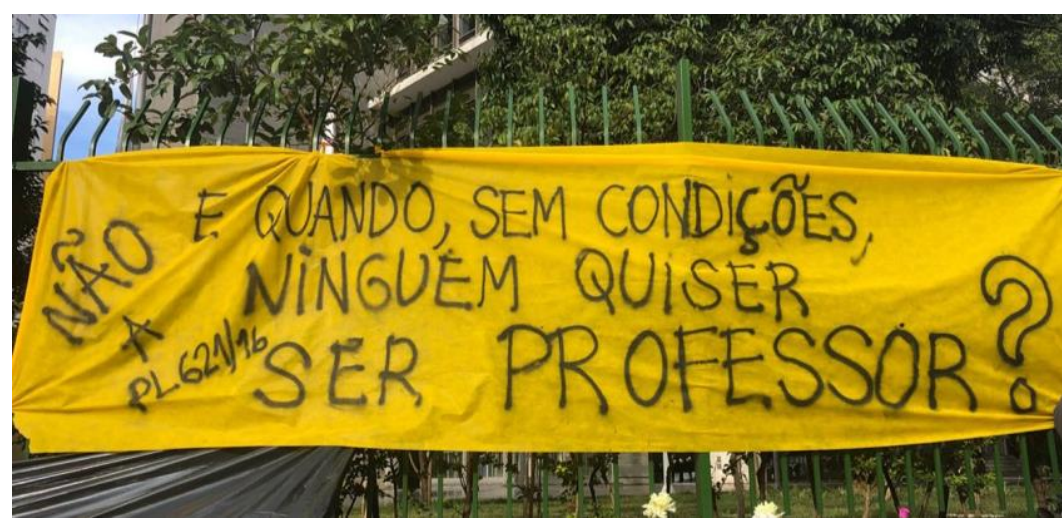


Fonte: Acervo particular da autora inspirada em foto reproduzida em Revista Escola

Figura 6 - Manifestação

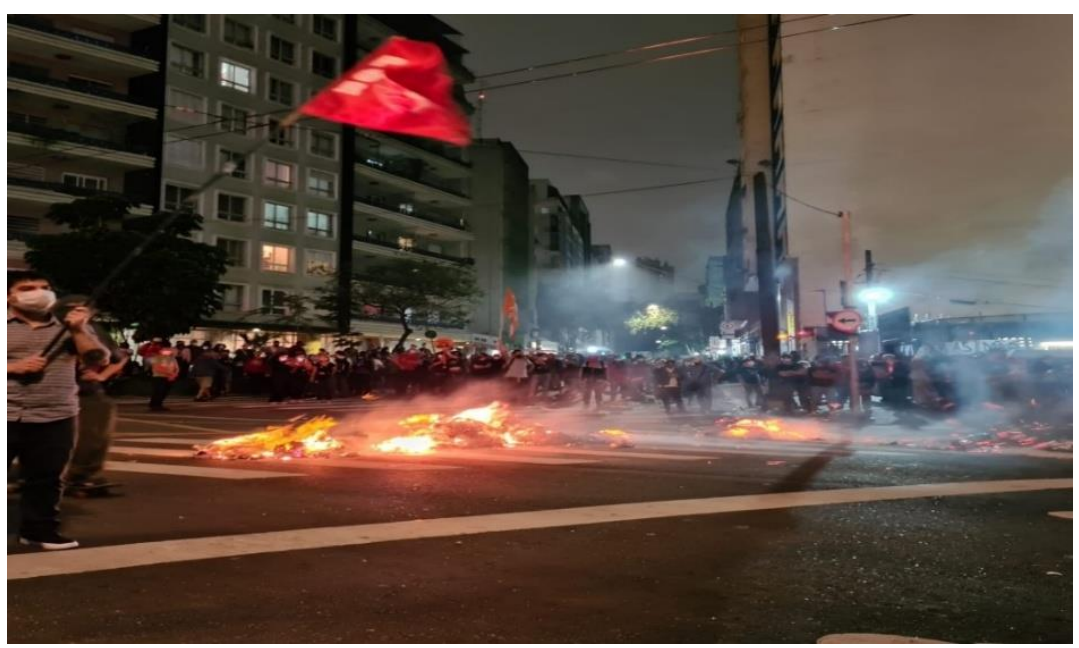

Fonte: Reprodução de fotografia publicada em Notícias Uol, 13/11/2021

Em diálogo com estas imagens de fatos recentes, inspirando-nos em seus escritos “cartas", escrevemos para você.

Mário, querido!!

A partir das reflexões e dos desafios que a emana de 22 nos apontou, talvez poderíamos reivindicá-la novamente, pelo que observamos e sentimos talvez, semanas de artes nos encheriam os corações de alegrias e de esperanças de um mundo menos duro e embrutecido. $\mathrm{O}$ que você pensa? O que falta? Artistas? Salões? Artes? Ideias?

Talvez não falte, aliás, certamente não falta.

Para muitos, o trabalho excessivo, o trabalho sem sentido que nos impede de ver, sentir, pensar, tanto, tanto... O trabalho toma proporções avassaladoras para mulheres e homens, mas especialmente para as mulheres.

Para muitos outros, o não trabalho. Vivemos hoje o recrudescimento da precarização do trabalho docente. Professoras e professores são trabalhadores sem condições, e sabemos, não se trata do cumprimento de uma missão diária. Como trabalhadores há direitos a serem cumpridos, outros a serem conquistados.

Veja Mário que ainda hoje, um século depois, poderíamos usar as suas palavras quando você se deparou com mulheres esmolando em Catolé da Rocha na Paraíba, "a dor, a imensa e sagrada dor do irreconciliável humano" (ANDRADE, 2015, p. 35). Cenas como estas são cotidianas e chegam a ser naturalizadas aos olhos de muitos. Fundamentamos nosso pedido de 
outras semanas de artes, primeiro porque poderíamos de fato comemorar este centenário, mas também porque a partir de pesquisas como a de doutorado intitulada Nem só de salário vivem as docentes de creche (2009), podemos verificar a importância que movimentos de resistências culturais podem desempenhar na vida das/os trabalhadoras/es.

Para você, que há tempos nos inspira tanto com os parques infantis na cidade de São Paulo (década de 1930), vamos te contar um pouco dessa pesquisa. Há uma análise de como as profissionais que exercem a função docente com as crianças de creche se constituem professoras por meio dos movimentos de resistências culturais via Sindicato dos Trabalhadores no Serviço Público Municipal de Campinas (STMC), com reivindicações por formações e valorizações profissionais, bem como e legitimamente condições de trabalho e salários dignos.

Dentre os materiais levantados na pesquisa no STMC, foram analisados dois cadernos de poesias, publicados a partir de concursos nessa entidade. Veja que interessante, uma entidade sindical que tinha em suas propostas de atuação a formação cultural e política da categoria, categoria esta de trabalhadores e trabalhadoras do serviço público. Muitas ações eram realizadas para efetivação destas formações. Uma delas era o aluguel de uma casa para além da sede do sindicato, que tinha por finalidade promover encontros, cursos, reuniões diversas para a constituição destas formações. Esta casa era alugada por dois sindicatos, este dos servidores municipais e pelo Sindicato dos Trabalhadores da Unicamp (STU). Era uma casa na região central da cidade, inclusive tombada pelo patrimônio histórico da cidade.

É importante destacar que ambos os sindicatos, o STMC e o STU, agregam diversas áreas de trabalho. O STMC contempla os seguimentos da educação, da saúde, da assistência social, do operacional e do administrativo e todos estes campos participavam de eventos e reuniões nesta casa de formação político-cultural.

Hoje a casa está lá, mas não mais para este fim nem como parte do sindicato. O STMC não atua mais com formações políticas e culturais com os trabalhadores e trabalhadoras, atua sim com um espaço de salão de beleza, em comemorações de aniversariantes dos seus filiados, e nem o salário tem sido pauta de reivindicações, a arte? Esta não se apresenta faz tempo...

O que esse movimento de formação político-cultural significou para os/as trabalhadoras da categoria em geral? E para os da educação? O que isso significou na constituição de cada professor/a? Mário, nos lembramos das trocas de cartas entre você e tantos amigos, mas particularmente, de uma delas escrita para Candido Portinari, em 23 de maio de 1938, em que afirmava seu desejo de proporcionar experiências cotidianas em arte para todas/es/os. Escrevia sobre a possibilidade de ter "coleçõezinhas" de livrinhos populares sobre pintores e escultores. 
Aracy Amaral (1989) nos leva a compreender que ele escrevia e buscava não os originais de obras artísticas. Preocupado com a exclusão de públicos, invés de formação, procurava criar condições para o acesso a todas elas e multiplicava seus desejos com amigos, como Portinari. Encontramos certo engajamento nessa forma de uma arte interessada em que sentimos as professoras/es também representados usufruindo de tantas formações.

A partir das análises dos documentos para a referida tese, encontra-se uma categoria organizada, presente em diversos momentos como reuniões no sindicato, em plenárias setoriais, em assembleias gerais e congressos da categoria, em movimentos na cidade. A história nos revela que muitas conquistas trabalhistas foram alcançadas nesse processo, como a redução da jornada de 40 horas para 36 horas semanais para todos/as os/as trabalhadores/as da prefeitura de Campinas e para as monitoras de creche de 36 horas para 32 horas semanais. Dentre outras conquistas salariais. Olha isso! A tão sonhada redução de horas de trabalho! E as mulheres, sim, pois estas eram e continuam sendo a grande maioria desta categoria de trabalhadoras na educação infantil. Mulheres podendo estudar, namorar, descansar, enfim, até quem sabe escrever mais poesias como esta publicada como uma das premiadas no II concurso do gênero:

Camaleão ${ }^{\text {viii }}$
Aqui na solidão dos meus pensamentos
Sinto o labirinto a minha volta
Mas o que pesa no peito
São as emoções
Intrigantes
Transformando-me em camaleão
Alegria/saudades/lágrimas/risos
Hora me convence
Hora me vence
Na espreita
O poder da palavra
Soberana
Aguardando solução
Pois existe o medo
Da resposta inesperada
Que pode anular
O explodir
Da emoção
Desejada..

Há uma rede de narrativas que se tece nos conflitos e conquistas realizadas pelas docentes de creche, deixando suas marcas no percurso da construção da profissão docente de creche. Para Benjamin (1995), a educação verdadeira é a que envolve reciprocidade, 
envolvendo culturas diferentes. Nesse sentido, os movimentos de resistências culturais podem redirecionar para uma construção da 'história dos vencidos'.

No caso, o sindicato representa a ideologia do coletivo, e a história pode ser construída nas experiências vividas, segundo Benjamin (1994, 1995), de modo coletivo. O neoliberalismo tenta anular os trabalhadores e as trabalhadoras enquanto pessoas, enquanto sujeitos da história. É justamente contra isso que os movimentos de resistências culturais lutam, pois os trabalhadores e trabalhadoras vivem, pensam, são pessoas inteiras e isso é inverter a lógica capitalista.

Devemos relembrar que você, entre tantos que se mostravam e acreditamos que de tantos que urge conhecer, também possuía um projeto pedagógico construído singularmente em sua epistolografia como demonstraram os estudos de Marcos de Moraes (2007) em que suas orientações ocorriam em forma escrita e amorosa com quem o procurava em busca de recomendações e reflexões ora sobre trabalhos de jovens artistas, ora sobre outras práticas que podíamos compreender como pedagógicas. Uma das cartas bastante conhecidas foi escrita em 16/02/1942 ao então jovem escritor Fernando Sabino, reproduzimos um trechinho apenas para retomá-lo como professor que também foi em suas cartas cujo potencial formativo requer ser reconhecido para que pensemos numa pedagogia em que as relações possam ocorrer horizontalmente e continuemos a questionar algumas práticas centradas exclusivamente na adulta ou no adulto professores:

Não há dúvida nenhuma que a arte tem entre os elementos que a constituem a insatisfação. A arte é filha da dor, dizem, e você repete na sua carta. Prefiro dizer insatisfação, que é mais dinâmico; e da insatisfação, a arte não é só filha, mas esposa, companheira cotidiana e mãe. $\mathrm{O}$ artista verdadeiro jamais estará satisfeito consigo mesmo nem com a obra de arte que produziu. Há satisfações momentâneas, está claro. E há, meu Deus! os satisfeitos... Mas você há de observar em toda a sua vida que os "satisfeitos" com sua missão e com as obras que realizam, nunca serão artistas "verdadeiros": são medíocres, são francamente ruins. Quanto às satisfações momentâneas, embora quase nunca elas sejam completas, nada de mais psicologicamente lógico. Você, como artista, cumpriu entusiasticamente, sem fadiga, o seu dever, isto é, deu tudo o que tinha. A obra de arte está realizada com todas as forças de qualquer espécie que você tem. É natural que você não veja. A obra de arte é você inteirinho, e todas as suas possibilidades críticas a consideram excelente. Não use então modéstia falsa: se diga com lealdade que você considera a sua obra excelente (ANDRADE, 1987, p. 33).

Contudo, ainda em nosso roteiro de casos e descasos, inspiradas em um de seus contos, o "Primeiro de Maio", escrito entre os anos de 1934-1942, envergamos a pensar sobre trabalhadoras e trabalhadores, em nosso caso, da educação e no seu, pelo conto, outros tantos e tantas cujo trabalho também era considerado menor. Atualmente, são muitos os descasos 
conosco, sim, somos professoras da educação básica e do ensino superior. No "Primeiro de Maio", você evoca o 35, um trabalhador da Estação da Luz, e seu vigor ao acordar neste dia destinado à comemoração do trabalhador. Mário de Andrade, em seu conto tão atual, você nos apresenta o processo de invisibilização de certos trabalhadores na cidade. O 35, como denominou a personagem, cruza São Paulo à procura de seus pares e parece encontrar o silêncio imposto por um grupo cujos interesses estão na contramão dos seus. Buscam afastar-se de qualquer comemoração possível. Afinal, o que havia para ser comemorado? Perguntamo-nos sobre isso nos anos 1930, quando inicia sua escrita, mas guardamos essa pergunta tantas décadas depois em que direitos são usurpados à luz do dia, sob nossos olhos.

Trazemos um fato recente ocorrido com as profissionais da educação pública do município de São Paulo. Em seus contos, cartas e documentos produzidos como primeiro diretor do Departamento de Cultura desta cidade muitos e originalíssimos projetos culturais foram feitos: cinema para crianças e suas famílias, a Biblioteca Municipal, os Parques Infantis, Bibliotecas Itinerantes, tantas coisas que podem nos inspirar até os tempos atuais. Pois bem, nessa mesma cidade, profissionais da educação básica resistiram em greve por mais de uma centena de dias contra a Reforma da Previdência que atinge a categoria - e não só - e faz alastrar um caminho de piora em suas condições de trabalho e de vida. Infelizmente, tal projeto não apenas foi aprovado como as professoras foram xingadas de "vagabundas" por um vereador tão jovem, mas com uma trajetória política bastante questionável. Mário, não bastasse isso, dias depois rajadas de gás foram jogadas contra manifestantes, majoritariamente professoras e professores, alguns e algumas já aposentados, pois a Reforma atinge diretamente essa categoria.

Não estamos mais turistando a partir da obra e reflexões geradas em O Turista Aprendiz, mas se tornou difícil entender a produção desse tempo como também de uma cultura do extermínio e da diminuição ou de dizimar populações inteiras, ou ainda, tornar profissões fundamentais para a formação humana e profissional em caráter inicial e continuado. Assustadoramente, e por isso ousamos chamar de terra arrasada, vão apagando histórias, vidas e lutas de muitas categorias, apagando-as vagarosamente ao mostrá-las como menos importantes ou substituíveis por aulas a distância, robôs e recursos didáticos que desconsideram saberes já acumulados e o caráter fundamental: a capacidade de criar, inventar e produzir conhecimentos.

Mas, Mário, bebamos da fonte de Paulo Freire, outro querido, para continuarmos existindo, resistindo e dizermos agora chega!! É diferente do "até dizer chega" presente numa viagem. Nosso "até dizer chega" é para outros espaços, relações e lugares. Dizemos chega para 
aqueles inóspitos, para o que põe basta à vida, para o que acirra as relações desiguais, ainda que usem palavras que parecem preocupar-se com seu fim, sendo jargão, em pouco ou nada contribuem para as mudanças estruturais, tão necessárias.

[...] em regime de dominação de consciências, em que os que mais trabalham menos podem dizer a sua palavra e em que multidões imensas nem sequer têm condições para trabalhar, os dominadores mantêm o monopólio da palavra, com que mistificam, massificam e dominam. Nessa situação, os dominados, para dizerem a sua palavra, têm que lutar para tomá-la. Aprender a tomá-la dos que a detêm e a recusam aos demais é um difícil, mas imprescindível aprendizado (FREIRE, 1987, p. 21).

Bora lá, sim Mário, você em suas viagens buscava fundamentalmente o nacional e uma cultura nacional e ao descobri-la viu-se diante das diferenças e desigualdades, o que provocou suas escritas e práticas políticas. Isto tudo se refletiu nas construções de palavras inusitadas, aproximadas de populações locais por onde andou, temos várias, como é próprio das relações e construções culturais, bora lá é uma delas. Mais que um chamamento simples, como "vamos", bora lá implica uns aos outros que vão bora. Então, implicados e implicadas, "bora lâ" pensar semanas de arte - e não só - que se esparramem e contem com as sabedorias e palavras dos dominados desse país?

\section{Referências}

AMARAL, ARACY. As artes plásticas na semana de 22. São Paulo: Perspectiva, 1989.

ANDRADE, Mário de. O turista aprendiz. Brasília: Iphan, 2015.

ANDRADE, Mário de. Cartas a um jovem escritor. Rio de Janeiro: Record, 1981.

ANDRADE, Mário de. Poesias completas. São Paulo: Círculo do Livro, 1976.

ANDRADE, Mário de. Poesias completas. Belo Horizonte: Itatiaia, 1987.

ANDRADE, Mário de. O Movimento Modernista. In: ANDRADE, Mário de. Aspectos da literatura brasileira. 5 ed. São Paulo: Martins, 1974.

BENJAMIN, Walter. Experiência e Pobreza. In: BENJAMIN, Walter. Magia e técnica, arte e política. São Paulo: Brasiliense, 1994, p.114-119.

BENJAMIN, Walter. O narrador: considerações sobre a obra de Nikolai Leskov. In:

BENJAMIN, Walter. Magia e técnica, arte e política. São Paulo: Brasiliense, 1995, p.197221. 
BUFALO, Joseane. Nem só de salário vivem as docentes de creche: em foco as lutas do Sindicato dos Trabalhadores no Serviço Público Municipal de Campinas (STMC 1988-2001). 179 f. Tese (Doutorado em Educação) - Faculdade de Educação, UNICAMP, Campinas,2009.

FREIRE, Paulo. Pedagogia do oprimido. Rio de Janeiro: Paz e Terra, 1987.

IANNI, Octávio. A ideia de Brasil moderno. São Paulo: Brasiliense, 2004.

JUCÁ, Beatriz. Duas crianças yanomami mortas, sugadas por uma draga da exploração ilegal de minério. El País Brasil, 15 out. 2021. Disponível em: https://brasil.elpais.com/brasil/202110-16/duas-criancas-yanomami-mortas-por-uma-draga-de-exploracao-ilegal-de-mineriodiante-da-omissao-dogoverno.html\#: :text=No\%20dia\%2012\%20de\%20outubro,nadar\%20e\%20sobreviver\%20ao \%20rio. Acesso em: 12 dez. 2021.

LOPEZ, Telê Ancona. O Turista Aprendiz na Amazônia: a invenção no texto e na imagem. Anais do Museu Paulista, São Paulo, v. 13, n. 2. p. 135-164, jul.-dez. 2005.

MORAES, Marcos Antonio de. Orgulho de jamais aconselhar: a epistolografia de Mário de Andrade. São Paulo: Edusp/ Fapesp, 2007.

VAZ, Sérgio. Do sarau da Cooperifa à Semana de Arte Moderna da Periferia. Portal Vermelho, 19 out. 2007. Disponível em: https://vermelho.org.br/2007/10/19/do-sarau-dacooperifa-a-semana-de-arte-moderna-da-periferia/. Acesso em: 30 jan. 2022.

ZIZEK, Slavoj. A ômicron e o que nos faz tolerar o intolerável. In: Outras Palavras. 10/12/2021. Disponível em: https://outraspalavras.net/crise-civilizatoria/omicron-e-o-quenos-faz-tolerar-o-insuportavel. Acesso em 02/02/2022.

\footnotetext{
'Em algumas passagens deste ensaio ao nos referirmos à Mário de Andrade será usado apenas Mário, seja pela aproximação que já sentimos com o poeta, seja para conferir certa leveza ao escrito.

ii As fotografias recentes podem ser encontradas em busca Google Imagens, entre aquelas livres de direitos autorais. Elas nos chocam e denunciam abusos e descasos políticos recentes e amplamente noticiados.

iii Esta frase foi usada de modo mais ostensivo em meados de 2004 quando a Associação Brasileira de Anunciantes (ABA) ao identificar que a autoestima do brasileiro estava em baixa julgou ser importante promovê-la. Tratou-se de anúncios de caráter propagandístico que remetiam a consumo e a não esmorecer diante de crises.

iv Esse ensaio foi escrito em dezembro de 2021, contudo, ao recebermos a revisão e o reorganizarmos, nos deparamos atônitas com mais um assassinato no Brasil. Um jovem imigrante congolês, torturado e morto a pauladas à luz do dia na cidade do Rio de Janeiro, Barra da Tijuca. Não poderíamos deixar de registrar isso ao mencionarmos o contexto e as condições em que escrevemos. É esse passado que não passa e se inscreve em nós à medida em que refletir sobre Semana de Arte Moderna, os registros deixados por Mário, nos remetem a pensar em belezas, mas também em tragédias e exclusões, que persistem e nos constituem sem humanidade. E juntos, nos fazem rever e repensar.

${ }^{v}$ Codaque era como Mário de Andrade escrevia abrasileirando a palavra Kodak, marca de sua câmera fotográfica

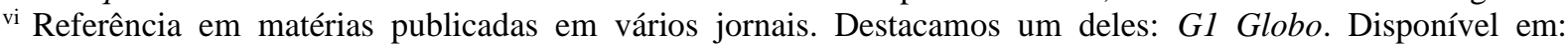
https://g1.globo.com/politica/noticia/2020/05/22/ministro-do-meio-ambiente-defende-passar-a-boiada-e-mudarregramento-e-simplificar-normas.ghtml. Acesso em: 12 dez. 2021.

vii Conforme entrevista dada ao Jornal CNN e publicada em 15 nov. 2021. Disponível em: https://www.cnnbrasil.com.br/nacional/fogo-na-amazonia-nao-tem-origem-natural-diz-coordenador-domapbiomas/. Acesso em: $12 \mathrm{dez} .2021$.

viii Poesia premiada no II Concurso do gênero promovido pelo STMC em 1993.
} 